\title{
PUBLIC EDUCATION ON SOURCES AND EFFECTS OF RADIOACTIVE WASTE DISPOSAL
}

\author{
J. E. MARTIN,* K. RENGAN** \\ *University of Michigan, School of Public Health, Ann Arbor, MI (USA) \\ **Chemistry Department, Eastern MichiganUniversity, Ypsilanti, MI 48197 (USA)
}

(Received November 9, 1992)

\begin{abstract}
A six-day workshop, developed for providing information on sources and effects of radioactive waste disposal to the general public, is described. The materials were used successfully with a group representing the general public. An extension of the workshop for high school and junior high school science teachers is discussed.
\end{abstract}

Many of the participants in the public discussions about low level radioactive wastes (LLRW) lack the factual information to be an effective opponent or proponent of a particular aspect of its management. This need not be the case, but unfortunately it is the usual situation because objective, unbiased information on basic radiological sciences and LLRW is not readily available, and what information exists is not in formats that are amenable for study and assimilation by the public.

The International Low-Level Radioactive Waste Research and Education Institute was established by the Michigan Legislature under PA 204 to be an independent professional body to provide the public basic resources on LLRW, including research on special questions and education for interested groups. The Institute is operated, based on a competetive proposal, by a consortium of faculty at the University of Michigan and Michigan State University. Direction is given by the Institute's Board of Governors who represent diverse interests regarding LLRW as called for in PA 204.

The Board of governors established as its number one priority a project on community education to promote understanding of radiation and radioactive materials and the origin and nature of LLRW and various public issues related to it. This paper discusses the approach and scope of this effort for the general public, and based on its successful development with public input, an approach to make the materials and resources available for science education.

\section{Background}

Radiological science modules have been developed for education of the general public on radioactive waste, with particular emphasis on basic concepts of radioactivity, its interactions and effects, and its waste significance. This information is basic to issues 
involved in public debate about LLRW management. Six, 6-hour modules were developed for the subject areas shown in Table 1. In order to make these materials available for public education, the following tasks were performed:

(1) A detailed training manual was prepared that developed modules which describe radiation, how radioactive materials come about, and several characteristics of LLRW materials and their management.

(2) Six computer-based tutorials were developed that were keyed to the written training manual.

(3) A test group of diverse public participants was assembled for testing of materials and presentation formats.

(4) Lectures were developed and presented in 6-hour modules that were keyed to the manual and the computer tutorials. The effectiveness of each were surveyed by annonymous questionnaires given to each participant.

The major goal of the project was to provide objective and factual information to the public. Two observations, in particular, shaped the scope and substance of the project. First, it is not entirely unanimous what radiological science information should be provided to members of the public interested in LLRW issues. It is obvious that the scope of material that could be presented is very broad and, consequently, considerable judgment needs to be exercised in selecting topics. The project focussed on basic information on what radiation is and how it behaves; a description of the materials in LLRW and processes that produce it; on the physical, chemical, biological and environmental behaviour of LLRW components and how they affect radiation dose over time and space; radiation risks; and selected technical issues on transportation, siting, environmental assessment, and the basis and content of control regulations. This orientation is decidely factual and substantially avoids the policy areas that are subject to politics and other judgments. The goal was to provide the data and factual concepts on LLRW that can go into the considerable deliberations upon which political judgments and social interpretations could be based, giving full recognition to those public processes. As an Institute committed to research and education, it was not the Institute's purpose nor desire to make these judgments for participants in LLRW debates; however, the role selected was to provide accurate unbiased technical information so that participants may provide technical support for whatever decisions they make on LLRW management.

Second, the amount of material that can be presented is also subject to considerable debate. Some argue that the public would never give up 100 or more hours to study the subject, and that the materials should fit into one or two evenings or a one-day workshop. The approach selected recognized that it simply takes 100 or more hours of study to learn the factual aspects of radiological sciences related to LLRW and that it should be offered to the public and let them decide. It was found that, given the choice, 
Table 1

Proposed modules for LLRW education

Module I - Radiation and its characteristics

1. Basic physics of the atom, energetics

2. Why and how atoms decay

3. Radiations, types and behavior

4. Isotopes, chant of nuclides, decay schemes

5. Mathematics of radioactive decay

6. Common radioactive materials, progeny

Module II - Radiation dose and bioeffects

1. Interactions of radiation with matter

2. Units of radiation dose, what they mean

3. Biological processes of radiation damage

4. Risk models - differences between models

5. Risk coefficients

Module III - Radioactive materials in wastes

1. Altemative energy sources; waste materials produced

2. Production of activation and fission products in nuclear energy wastes

3. Processes that produce LLRW

4. Typical LLRW streams

Module $N$ - Physical, chemical, environmental behavior of LLRW

1. LLRW waste forms

2. Disposal modes

3. Environmental transport modes, various nuclides

4. Significant radionuclides

5. Behavior of LLRW over time

6. Past disposal history, effects

Module $V$ - Envimonmental effects of LLRW management

1. Disposal options, selected designs

2. Environmental assumptions for designs used

3. Nuclides selected; why, source terms

4. Risk analysis; projections of releases, effects

5. Projected health effects

Module VI - Control of LLRW Disposal

1. Standards, criteria and regulations

2. Concepts for control

3. Basic assumptions for controls, design of regulations to achive them

4. Public protection goals

5. Regulatory approach; significant regulations (Federal and State)

6. Basic components of regulations 
many people would make the effort. About twothirds of the test group made the effort, and they felt privileged to have had the opportunity. The modular concept also accomodated a range of interests in that some participants selected only those topics of most interest to their needs.

Numerous public forums are anticipated in the course of siting, designing, constructing and operating a LLRW site. Many, if not most, of these will be oriented toward public and policy issues offering full opportunity to debate the various public interests represented. The Institute determined that it need not and probably should not undertake to assure that a forum is provided for such debates; instead it should provide a mechanism for participants to be equipped with good understanding of the technical essentials of the subject so they can debate their particular interests more effectively. The training format selected is believed to have accomplished this purpose.

\section{Training format}

Development of materials was a major part of the project primarily because of the need to provide it in formats readily usable by the public. Resource materials were presented at a level similar to that in the average newspaper in two formats: (1) a comprehensive manual broken down into the six modules presented, and (2) an interactive computer-based tutorial designed to be a reinforcement of the concepts presented in the written manual. The computer turials were user-friendly, interactive, self-guiding and correcting, and used some dynamic graphics to illustrate concepts. A program called COURSE BUILDER, available for the MacIntosh computer, allowed dynamic graphics to be presented.

Once the manual and tutorials were developed, a test phase was implemented using the two in combination with six lecture modules encompassing about 36 hours of class time. The test group consisted of twenty persons from diverse backgrounds, primarily teachers, local officials, business people, and heads of families. Several communities were represented. Participants had considerable interest in the LLRW issue, and some were from the areas initially considered for potential LLRW siting.

The effectiveness of delivering the materials was determined by anonymous questionnaires to obtain critiques of material and presentation efficiency, and individual interviews to gain suggestions on improving materials in all forms. Appropriate changes have been made in the materials, and they are available when so requested to be offered to other groups that may request them. This approach has the potential to build a base of knowledgeable people within the community who can help those who participate in follow up presentations. It may also lend itself to training trainers in the community and letting them conduct a large part of the exercises with Institute backup and support. 
The Institute has learned that a key aspect of public education is to offer to make the resources on public information generally available, but that any actual training should only be conducted upon request by a particular community group. When a community requests detailed training, they select the group to be trained. Manuals would be provided to the group, and two computers would be placed at a central location for persons to access (or they could use personal computers). Lectures would be in blocks of about 6 hours (two evenings or a Saturday) with a break of one to two weeks for reinforcement and preparation using the manuals and the tutorials. The material can be elected in modules for persons interested in selected parts; however, both the manual and computer tutorials provide comprehensive treatment of radiological sciences specifically applied to LLRW.

\section{Adaption to science teaching}

Attempts by public schools to provide basic science information in ways that are interesting and attractive to students are constrained because objective, unbiased, and understandable information on these topics is not readily available. Existing information is also not in formats that are for presentation and assimilation by students. This is particularly the case for radiation, radioactivity, energy concepts and altematives, and radioactive wastes.

Since a comprehensive entry-level manual and user-friendly computer-based tutorials exist and have been shown to be effective, these can be modified and made available to high school and junior high school science teachers. The format for such use will be determined by science teachers themselves through participation in hands-on learning workshops. It is believed that providing similar materials to skilled science teachers will help not only to provide factual and understandable information on this important area of science, but when done properly, will attract others to study science once they discover that learning is straightforward and interesting. The instruction materials will be used to train the trainers (the teachers) by upgrading their skills, and, based on their advice, will be modified to best serve their science teaching needs.

The existing modules contain material on nuclear concepts, radiation, radioactivity, radiation bioeffects, sources and types of radioactive wastes, and general approaches to their control (See Table 1). These materials can be made available for use in high school and junior high school science programs as follows:

(1) Assemble an advisory committee (2 public, one LLRW institute, one industry, and one educator) to review implementation of training materials. This committee will meet about six times, mostly in the early stages of the project. 
(2) Assemble a group of 20 science teachers and use the existing training manual and computer tutorials to instruct them about radiation, how radioactive materials come about, alternative energy/waste sources, and several characteristics of LLRW materials. This will take 6-8 weeks, and will require extensive feedback mechanisms and followup reviews.

(3) Based on the science teacher critiques and needs, revise the written training manual into instruction units, and revise the computer-based tutorials accordingly.

(4) Prepare lecture outlines that are keyed to the instruction units in the manual and the computer tutorials.

(5) Assemble a second test group of 20 science teachers to test the effectiveness of using the revised teaching materials and presentation formats.

Since the existing materials are in formats that are readily usable by the general public, they are expected to be even more useful in the hands of skilled science teachers. The computerbased tutorials are expected to provide a useful dimension for science teaching to reinforce concepts presented in the written units. They are user-friendly, interactive, self-gulding and correcting, and they use dynamic graphics to illustrate concepts. Previous work with the public test group demonstrated that the computer tutorials could be very useful, especially for reinforcing written and lecture materials.

The existing manual and computer tutorials will be revised to make them most useful to science teachers. These revisions will be discussed with the first test group and the Advisory Committee. They will be tested again with a second group of science teachers to do two things: (1) to assure their effectiveness for teaching students, and (2) to provide the skills and information for science teaching to 20 additional teachers. Lectures for the teachers would be in two to three-hour blocks with breaks for reinforcement and preparation using the manuals and the tutorials. Teachers can use the material in units for the particular interests they wish to address; however, both the manual and computer series would provide comprehensive treatment of the subjects of radiation, radioactivity, energy/waste alternatives, and LLRW issues. Selection of teachers will emphasize communities with interest in LLRW issues and/or siting and schools with significant enrollments of minority and disadvantaged students.

Several reviews will be conducted to determine the effectiveness of delivering the materials, and anonymous questionnaires will be used to obtain critiques of material and presentation efficiency. Individual interviews will be conducted to gain suggestions on improving materials for use in science education. Once the manuals and tutorials are developed with science teacher input, it is envisioned that various teachers would then use them in their own teaching. Manuals or units would be provided for these classes, and computers would need to be available for student access. 


\section{Summary}

One of the major concepts behind the formation of the International LLRW Research and Education Institute was to provide objective and factual information to the public. A community education project sponsored by the LLRW Institute developed materials on radiological sciences for presentation in lectures, a public education manual, and user-friendly computer tutorials; these were successfully tested with a group representing the general public. A new project has been planned for high school and junior high school science education which builds upon the success of the earlier project in shaping science teaching goals for this subject not entirely unanimous what information should be provided to the public nor what formats are appropriate. The scope of material presented science teachers will adjust the existing materials for delivery by a series of workshops, including the scope and details of subjects to be covered. Placing relevant and tested materials in the hands of skilled science teachers is expected to contribute to their potential success in science education for radiological science. 